\title{
Occupational Health Surveillance: Pulmonary Function Test in Proppant Exposures
}

\author{
Humairat H. Rahman, Giffe T. Johnson, Raymond D. Harbison \\ Center for Environmental and Occupational Risk Analysis and Management, Department of Environmental and \\ Occupational Health, College of Public Health, University of South Florida, Tampa, FL, USA \\ Email: humairat@mail.usf.edu
}

Received 5 April 2016; accepted 9 May 2016; published 12 May 2016

Copyright (C) 2016 by authors and Scientific Research Publishing Inc.

This work is licensed under the Creative Commons Attribution International License (CC BY).

http://creativecommons.org/licenses/by/4.0/

(c) (i) Open Access

\begin{abstract}
Workers involved in hydraulic fracking processes are exposed to various types of chemicals and dusts in their workplaces, such as proppants, which hold open the fissures created in the fracking process. Recently, ceramic proppants have been developed that may be less hazardous to workers than traditional proppants. Pulmonary function testing of workers producing ceramic proppant was used to assess the potential inhalation hazards of ceramic proppant. 100 male workers from a producer of ceramic proppant were evaluated with pulmonary function test data collected and evaluated using The American Thoracic Society (ATS) acceptability criteria. A comparison group was selected from the Third National Health and Nutrition Examination Survey (NHANES III) spirometry laboratory subset. No pulmonary function deficits were found in the worker group in comparison to the NHANES III population. Mean FEV1 and FVC values in workers were 3.8 and 4.8 liters respectively, and were greater as compared to the NHANES III population of similar demographics. An FEV1/FVC ratio of less than 0.8, when compared to the NHANES III group, produced an odds ratio of 0.44 in worker group, indicating less risk of preclinical pulmonary dysfunction. Overall, exposure to ceramic proppant was not found to produce an adverse impact on pulmonary function in workers engaged in the manufacture of ceramic proppant.
\end{abstract}

\section{Keywords}

Proppant, Hydraulic Fracking, Pulmonary Function Test, Proppant Workers

\section{Introduction}

Scientists are continuously looking for alternative resources to meet the global energy demands of the 21st cen-

How to cite this paper: Rahman, H.H., Johnson, G.T. and Harbison, R.D. (2016) Occupational Health Surveillance: Pulmonary Function Test in Proppant Exposures. Occupational Diseases and Environmental Medicine, 4, 37-45. 
tury. Recovering gas and oil from unconventional gas in ways safer for workers and area residents' alike poses challenges to meet the increasing modern lifestyle need [1] [2]. Gas and oil industries are important resources in the economy; in 2006, nearly 380,000 workers were employed in the gas and oil industry. In the US, approximately, 1300 drilling companies were established since 2003 to 2006 [3] [4].

Hydraulic fracturing (fracking) technology is a process where both vertical and horizontal drilling are necessary to collect unconventional gas and oil. Proppants are tiny granules which settle in fissures either as a single layer or as a closed pack form to ensure continuous gas or oil collection [5]. Proppants "prop open" shale rock fissures and increase the production of unconventional gas and oil from wellbore. Ideal proppants require proper conductivity, permeability, density, crush resistance capacity, and acid resistance properties that helps to keep the rock crack or fissure open underground. Because proppants are used several miles from ground level, it is very important to utilize high quality proppant in the hydraulic fracking process [6].

Ceramic and silica based sand are the two primary type of proppants used in the industry. Silica contains respirable crystalline which pose an occupational pulmonary hazard [7]. Exposure to silica in workers who are involved in hydraulic fracking procedure is very common, making hydraulic fracking workers a vulnerable group for developing diseases related to respirable crystalline silica. From 2000 to 2005, 162 deaths were recorded from occupationally-induced silicosis in the United States [8]. To ensure safer workplaces, the use of proppants containing less silica is preferential. The use of non-silica ceramic proppants are under examination to determine their feasibility as a sand replacement [9].

Currently, ultra-light weight proppant materials can be either a single material type or a mix of hard-soft materials [10] [11]. These mixtures also have different particle shapes such as prismatic, rounded ceramic, or walnut shell [12]. Experiments have shown that silica-free, ceramic proppant of rounded size is the better choice in comparison to other proppants available in the market [6]. The evaluation of proppants for suitability involves various tests like single particle compression, crush, particle settlement, and conductivity tests [13].

As ceramic proppants contain little to no silica, they may become the preferred choice for health reasons. The purpose of this study is to determine whether exposure to non-silica ceramic proppant in an industrial setting poses a pulmonary health risk to exposed workers. This evaluation was made by comparing the pulmonary function results of workers engaged in the manufacture of ceramic proppant to pulmonary function results from the general population found in the Third National Health and Nutrition Examination Survey (NHANES III) data set.

\section{Methods}

This study evaluated workers in a ceramic factory with Pulmonary Function Test (PFT) data as a result of evaluating fitness to wear a respirator in the workplace. The study population included male workers $\geq 18$ years old with maximum and minimum heights of $\leq 76$ and $\geq 61$ inches respectively. Demographic data relevant to pulmonary function assessment measured included: age, height, smoking status, and race. The NHANES III pulmonary function subset, restricted by the age and height ranges (and gender) of the worker population, was used for comparison to a normal population. American Thoracic Society (ATS) guidelines were followed for acceptable pulmonary function test and all pulmonary function tests were reviewed by a physician for acceptability [14] [15]. The best values of FEV1, FVC, and FEV1/FVC ratio were taken from the spirometry record for use in data analysis.

The research protocol was approved by the University of South Florida Institutional Review Board (IRB) number 00001348.

\subsection{Proppant Worker Population}

FEV1(in liters), FVC (in liters), and FEV1/FVC data for the proppant workers were selected from spirometry records provided by the Occupational Health and Support Services (OHSS), a medical care company that specializes in providing medical support personnel for testing and compliance needs.

FVC (Forced Vital Capacity) is the maximum volume of air that can be exhaled forcefully by a person after a maximum inhalation. FEV1 (Forced Expiratory Volume in 1 second) is the amount of air that can be expired forcefully from the lung in one second after maximum inspiration. In this study, percent predicted values were not used to determine normalcy for individuals; rather a direct comparison between the worker population and a control population was made in aggregate by comparing all "best" values in the groups, with the control group being restricted by the age and height ranges, as well as gender, of the worker group.TheFEV1/FVC ratio was evaluated as an indicator of early potential obstructive impairment if the value of the ratio was $<80 \%$. 
Inclusion criteria for the proppant workers included $>18$ years and older, and having undergone spirometry testing. Age, gender, race, smoking history and height information were recorded for each subject to identify possible confounders that may have had an effect on pulmonary function.

Koko spirometry was used to measure pulmonary function in the proppant workers. The best value out of 3 attempts from spirometry reading was taken for final analysis. The FEV1 and FVC reading were expressed in liters. Spirometry records for 316 proppant workers were made available for the study through OHSS. After assessing the records for inclusion criteria, agreement with American Thoracic Society (ATS) spirometry criteria and the removal of duplicate entries, 101 subjects remained for statistical analysis: 100 male workers and 1 female worker. The female worker was removed from the dataset because of the limited statistical power for categorization by gender, leaving a final dataset of 100 male workers.

\subsection{NHANES III Population}

The NHANES III pulmonary function subset comprised the control population, and was same inclusion criteria and personal information were selected as was for the proppant workers, which then additionally restricted by the age and height range found in the worker population and restricted by male gender. Similarly, FEV1, FVC, and FEV1/FVC values were taken from the raw spirometry data publicly available for the NHANES III population. The comparison group included pulmonary function tests for 130,691 people. The file of raw spirometry data was merged with the Adult Household file from the NHANES III record to obtain the same demographic as was available for the proppant workers. The Spirometry tests for the NHANES III population were conducted according to the guidelines from ATS. Participants performed the test (5 to 8 times) according to the spirometry protocol. The final population used was $\mathrm{n}=6662$.

\subsection{Data Analysis}

The student's t-test was used to compare lung function variables of FEV1 and FVC in the proppant workers group and the NHANES III (Table 2). Further analysis was conducted by stratification of height, age, race and smoking status (Table 3). We also conducted stratification of variables including age, height, race, smoking status in the study population to identify the individual effect of these variables differences on evaluation of proppant workers status on pulmonary function. Stratification was performed by dividing the sample by median age and height, and dividing the sample by the categorical variables of race and smoking status (yes/no).

Multivariate linear regression analysis was conducted to estimate which factors are the most predictive of lung function for FEV1 and FVC outcomes. The variables evaluated included: age, height, smoking history (pack years) and race. To evaluate factors that potentially predict lung obstruction, the FEV1/FVC ratio was used as an outcome in logistic regression. The study evaluated the worker population for lung function deficits at the higher end of the normal FEV1/FVC of 0.80 as a conservative screen for preclinical pulmonary obstruction.

The cut off point for p-value for statistical significance was set at $<0.05$ for all analysis. SAS version 9.4 was used for statistical analysis.

\section{Results}

\subsection{Univariate Analysis}

The demographic information for both the proppant workers (study population) and the NHANES III population (comparison group) used for analysis is shown in Table 1. The study population was male only and $31 \%$ of them had positive smoking history. Eighty percent of subjects were taller than median height (69 inches) and 54\% subjects were less than median age (39 years). Eighty five percent of the study population identified as white.

The mean results of FEV1 and FVC when compared to the overall proppant workers with the NHANES III population are shown in Table 2. Table 2 shows that the FEV1 of the proppant workers was 3.8 and the NHANES III was 3.3 with a p-value of $<0.001$. This indicates that the 0.5 difference between the FEV1 of these two samples was statistically significant. The Confidence Interval (CI) for proppant workers was 3.66 - 3.92 . The CI of NHANES III was 3.30 - 3.35. The FVC of proppant workers was 4.8 and NHANES III was 4.3 with a p-value of $<0.0001$. This indicates that the FVC difference of 0.5 between the proppant workers and the NHANES III was statistically significant. The proppant workers population showed higher mean values of both FEV1 and FVC when compared to the NHANES III population. 
Table 1. Demographic information of male proppant workers and NHANES III population.

\begin{tabular}{ccc}
\hline Demographic Information & Proppant Workers & NHANES III \\
\hline Total Population & 100 & 6662 \\
Smoking History (Yes) & 31 & 4165 \\
Smoking History (No) & 69 & 2499 \\
Median Height ( $\geq 69$ inches) & 80 & 3733 \\
Median Height (<69 inches) & 20 & 2929 \\
Median Age ( $\geq 39$ years) & 46 & 2634 \\
Median Age (<39 years) & 54 & 4028 \\
Race (White) & 85 & 4562 \\
Race (Black) & 15 & 1876 \\
\hline
\end{tabular}

Table 2. FEV1 (l) and FVC (l) mean comparison for overall population.

\begin{tabular}{cccc}
\hline & Overall Male Population: Without Stratification & \\
\hline FEV1 (Liters) & Mean Value & $\mathbf{9 5 \%}$ CI & P Value \\
\hline Proppant Workers & 3.8 & $3.66-3.92$ & $<0.0001$ \\
NHANES III & 3.3 & $3.30-3.35$ & $\mathbf{9}$ Palue \\
FVC (Liters) & Mean Value & $\mathbf{9 5 \%}$ CI & $<0.0001$ \\
Proppant Workers & 4.8 & $4.63-4.94$ & $4.30-4.35$ \\
NHANES III & 4.3 & & \\
\hline
\end{tabular}

Table 3 compares the result for the proppant workers with the NHANES III population of FEV1 and FVC after stratification by smoking status, median height, median age, and race. Smoking status (yes/no), median height ( $\geq 69$ inches and $<69$ inches), median age ( $<39$ years), and race (white) were statistically significant $(\mathrm{p}<$ 0.05 ) for both FEV1 and FVC when compared with the proppant workers with the NHANES III population. The means of the FVC were statistically significant ( $\mathrm{p}$ value $<0.05$ ) for the proppant workers who were of median age $\geq 39$ years. However, the means of FEV1 were not statistically significant ( $p$ value 0.372 ) for the proppant workers who were of median age $\geq 39$ years. The means of the FEV1 and FVC were not statistically significant with p value of 0.1232 and 0.9489 respectively for the proppant workers who indicated their race as black.

\subsection{Multivariate Analysis}

The multivariate linear regression analysis results are shown in Table 4 and Table 5 for FEV1 and FVC respectively. The multivariate analysis findings showed that median age, race, smoking history and median height were statistically significant $(\mathrm{p}<0.05)$ when associated with FEV1, however, the association was not statistically significant for worker's status ( $\mathrm{p}>0.05$ ). The analysis also showed that median age, race, smoking history and height were statistically associated with FVC, however, proppant workers status was not a significant predictor of FVC or FEV1(p > 0.05).

\subsection{Logistic Regression Analysis}

Logistic regression analysis was conducted to identify the influence of variables on the FEV1/FVC ratio, since the FEV1/FVC ratios $<0.8$ can be indicative of a preclinical pulmonary obstruction. Table 6 shows the variables that were evaluated to predict a change in pulmonary function: median age, race, smoking history, and median height for the proppant workers and the NHANES III population. Subjects with a median age of 39 or older have 3.6 times higher chance to generate an FEV1/FVC $<0.8$. Those subjects self-identifying as black showed a decreased risk of generating a FEV1/FVC ratio $<0.8$, with an odds ratio of 0.76 . While height did not demonstrate an association with this outcome, smoking status produced a small effect, which is not likely to be meaningful compared to other variables evaluated. Overall, proppant workers were 0.44 times less at risk to develop an FEV1/FVC ratio of $<0.8$, demonstrating a modest protective effect from worker status. 
Table 3. FEV1 (l) and FVC (l) mean comparison for the proppant workers and the NHANES III for smoking, median height, median age, and race.

\begin{tabular}{|c|c|c|c|}
\hline \multicolumn{4}{|c|}{ Smoking Status: Yes } \\
\hline FEV1 (Liters) & Mean Value & 95\% CI & P Value \\
\hline Proppant Workers & 3.5 & $3.26-3.82$ & \multirow[b]{2}{*}{0.01} \\
\hline NHANES III & 3.2 & $3.15-3.21$ & \\
\hline FVC (Liters) & Mean Value & $95 \% \mathrm{CI}$ & $P$ value \\
\hline Proppant Workers & 4.6 & $4.28-4.87$ & \multirow{2}{*}{0.03} \\
\hline NHANES III & 4.2 & $4.2-4.27$ & \\
\hline \multicolumn{4}{|c|}{ Smoking Status: No } \\
\hline FEV1 (Liters) & Mean Value & $95 \% \mathrm{CI}$ & P Value \\
\hline Proppant Workers & 3.9 & $3.76-4.04$ & \multirow{2}{*}{$<0.001$} \\
\hline NHANES III & 3.6 & $3.52-3.59$ & \\
\hline FVC (Liters) & Mean Value & $95 \% \mathrm{CI}$ & P Value \\
\hline Proppant Workers & 4.9 & $4.69-5.06$ & \multirow{2}{*}{$<0.001$} \\
\hline NHANES III & 4.5 & $4.42-4.50$ & \\
\hline \multicolumn{4}{|c|}{ MEDIAN HEIGHT $\geq 69$ inches } \\
\hline FEV1 (Liters) & Mean Value & $95 \% \mathrm{CI}$ & P Value \\
\hline Proppant Workers & 3.8 & $3.67-3.97$ & \multirow{2}{*}{$<0.0001$} \\
\hline NHANES III & 3.5 & $3.47-3.53$ & \\
\hline FVC (Liters) & Mean Value & $95 \%$ CI & P Value \\
\hline Proppant Workers & 4.9 & $4.69-5.06$ & \multirow{2}{*}{$<0.02$} \\
\hline NHANES III & 4.6 & $4.55-4.61$ & \\
\hline \multicolumn{4}{|c|}{ MEDIAN HEIGHT $<69$ inches } \\
\hline FEV1 (Liters) & Mean Value & $95 \% \mathrm{CI}$ & P Value \\
\hline Proppant Workers & 3.7 & $3.37-3.95$ & \multirow{2}{*}{0.0006} \\
\hline NHANES III & 3.1 & $3.06-3.13$ & \\
\hline FVC (Liters) & Mean Value & $95 \%$ CI & P Value \\
\hline Proppant Workers & 4.5 & $4.11-4.80$ & \multirow{2}{*}{0.027} \\
\hline NHANES III & 4.0 & $3.96-4.02$ & \\
\hline \multicolumn{4}{|c|}{ Median Age $\geq 39$ Years } \\
\hline FEV1 (Liters) & Mean Value & $95 \% \mathrm{CI}$ & P Value \\
\hline Proppant Workers & 4.0 & $3.9-4.16$ & \multirow{2}{*}{0.372} \\
\hline NHANES III & 4.0 & $3.94-3.99$ & \\
\hline FVC (Liters) & Mean Value & $95 \% \mathrm{CI}$ & P Value \\
\hline Proppant Workers & 5.1 & $4.9-5.2$ & \multirow{2}{*}{0.017} \\
\hline NHANES III & 4.9 & $4.88-4.9$ & \\
\hline Median Age $<39$ & & & \\
\hline
\end{tabular}




\section{continued}

\begin{tabular}{|c|c|c|c|}
\hline FEV1 (Liters) & Mean Value & $95 \%$ CI & P Value \\
\hline Proppant Workers & 3.6 & $3.38-3.79$ & \multirow[b]{2}{*}{$<0.0001$} \\
\hline NHANES III & 2.9 & $2.87-2.93$ & \\
\hline FVC (Liters) & Mean Value & $95 \%$ CI & P Value \\
\hline Proppant Workers & 4.6 & $4.30-4.80$ & \multirow{2}{*}{$<0.0001$} \\
\hline NHANES III & 4.0 & $3.93-3.99$ & \\
\hline \multicolumn{4}{|l|}{ Race: White } \\
\hline FEV1 (Liters) & Mean Value & $95 \%$ CI & P Value \\
\hline Proppant Workers & 3.8 & $3.66-3.98$ & \multirow{2}{*}{$<0.0001$} \\
\hline NHANES III & 3.4 & $3.36-3.41$ & \\
\hline FVC (Liters) & Mean Value & $95 \%$ CI & P Value \\
\hline Proppant Workers & 4.8 & $4.67-5.02$ & \multirow{2}{*}{$<0.0001$} \\
\hline NHANES III & 4.4 & $4.41-4.48$ & \\
\hline \multicolumn{4}{|l|}{ Race: Black } \\
\hline FEV1 (Liters) & Mean Value & $95 \%$ CI & P Value \\
\hline Proppant Workers & 3.3 & $3.12-3.20$ & \multirow{2}{*}{0.1232} \\
\hline NHANES III & 3.2 & $3.10-3.58$ & \\
\hline FVC (Liters) & Mean Value & $95 \%$ CI & P Value \\
\hline Proppant Workers & 4.0 & $3.66-4.40$ & \multirow{2}{*}{0.9489} \\
\hline NHANES III & 4.0 & $3.97-4.06$ & \\
\hline
\end{tabular}

Table 4. FEV1 variables from multivariate linear regression analysis.

\begin{tabular}{cccc}
\hline & FEV1 (Liters) & & \\
\hline Variable & Parameter Estimates & Standard Error & P-Value \\
\hline Median Age (39 Years) & -0.98 & 0.0005 & $<0.0001$ \\
Race (Black vs White) & -0.31 & 0.02 & $<0.0001$ \\
Smoking History (pk-yrs) & -0.31 & 0.0006 & $<0.0001$ \\
Median Height (69 Inches) & 0.41 & 0.02 & $<0.0001$ \\
Proppant Workers vs NHANES III & 0.11 & 0.07 & 0.13
\end{tabular}

Table 5. Variables of FVC from multivariate linear regression analysis.

\begin{tabular}{|c|c|c|c|}
\hline \multicolumn{4}{|c|}{ FVC (Liters) } \\
\hline Variable & Parameter Estimates & Standard Error & P-Value \\
\hline Median Age (39 Years) & -0.88 & 0.02 & $<0.0001$ \\
\hline Race (Black vs White) & -0.45 & 0.02 & $<0.0001$ \\
\hline Smoking History (pk-yrs) & -0.003 & 0.009 & $<0.0001$ \\
\hline Median Height (69 Inches) & 0.56 & 0.02 & $<0.0001$ \\
\hline Proppant Workers vs NHANES III & 0.08 & 0.08 & 0.32 \\
\hline
\end{tabular}


Table 6. Odds ratio estimates by logistic regression analysis (FEV1/FVC < 0.80).

\begin{tabular}{ccc}
\hline Effect & Odds Ratio & 95\% CI \\
\hline Median Age ( $\geq 39$ Years) & 3.61 & $3.19-4.07$ \\
Race (Black vs White) & 0.76 & $0.69-0.95$ \\
Smoking History (pk-yrs) & 1.03 & $1.03-1.04$ \\
Median Height ( $\geq 69$ inches) & 1.12 & $0.99-1.26$ \\
Proppant Workers vs NHANES III & 0.44 & $0.28-0.67$ \\
\hline
\end{tabular}

\section{Discussion}

Studies conducted on workers' pulmonary function using spirometry measurements of FEV1, FVC, and the FEV1/FVC ratio have observed significant differences for workers exposed to harmful substances [16]-[21]. Thus, measuring FEV1, FVC and FEV1/FVC output from spirometry readings is a reliable screening test to observe anormal or abnormal lung function. The current study was done to assess the potential impact of ceramic proppant production on pulmonary function in workers. No results were produced that indicate proppant manufacturer workers were at increased risk for pulmonary function impairment compared to a general population. In several instances, the results indicate that the worker group evaluated may experience the 'healthy worker effect' in that they demonstrated statistically significantly higher pulmonary function as a group, compared to a baseline population.

FEV1 analysis in our study showed that median age (years), race (black vs. white), and smoking history (in pack-years) affected the pulmonary function of proppant workers. Each unit increase in median age, race, and smoking history decreased FEV1; each unit increased in height above 69 inches (median height) increased FEV1. The effect of race on FEV1 was found to be statistically significant, with black study population showing a lower mean FEV1 value than the mean FEV1 value of the white study population. Thus the black population had higher risk for lower pulmonary function volumes than the white population workers, though these changes may not be of clinical significance. This finding is also supported by the previous studies conducted on lung function tests in African American population [22]-[24]. Each unit increase in pack-years of smoking was associated with a decrease in FEV1, while a unit increase in height was associated with higher FEV1 in the workers. Our study showed that smoking leads to a modest decline of pulmonary function volumes compared tononsmokers. Other studies conducted on smoking and the impact on lung function have observed similar associations [25]-[27].

Overall, the mean FEV1 in the proppant workers was found to be more than the NHANES III sample signifying that the worker population, as a group, had better lung function values than the comparable NHANES III population. However, this association was not statistically significant ( $\mathrm{P}$ value $>0.05$ ). Similar observations were obtained from multiple linear regression analysis using FVC. Each unit increase in median age, race and smoking history demonstrated decreases in FVC. Increases in median height showed increased results for FVC. Each yearly increase in age and smoking was significantly associated with a lowered FVC. The black study population were found to have lower FVC than the white study population, which was statistically significant. As with FEV1, each inch increase in height was significantly associated with increase in FVC. The mean FVC in the proppant workers was greater than the mean of the NHANES III sample. However, this difference was not statistically significant (P value $>0.05$ ). The proppant workers did not show any statistical association for FEV1 and FVC. The analysis of FEV1 as well as FVC validates that the variables such as height, age, smoking history and race that are known to be associated with pulmonary functions measures do, in fact, impact these measurements.

The logistic regression analysis demonstrated a protective effect regarding the prediction of preclinical obstructive disorders in proppant workers $(\mathrm{OR}=0.44)$ using an FEV1/FVC ratio $<0.8$ when compared with the NHANES III. The logistic regression analysis demonstrated that those aged 39 years or older had 3 times greater risk in developing obstructive type of lung impairment (FEV1/FVC ratio $>0.8$ ). Previous studies have also established that lung function tests decrease in older populations [28]-[31]. The results showed that older workers have higher propensity to have lower lung function values than the general population.

While this study was conducted among workers engaged in the manufacture of ceramic fracking proppant, and not those using proppant to frack oil and gas wells, the results indicate that the use of ceramic proppant may 
provide a safer alternative to high silica containing sand proppants. Our analysis found that exposure to proppant in an adequately managed environment did not lead to loss of pulmonary function in workers compared to that of a control population.

\section{Limitations}

The principal limitation of this study was the comparatively small sample set of proppant worker data that was available for analysis. Likewise, more data on different forms of ceramic proppant produced and the specific durations of exposure would have allowed greater effect analysis. An additional limitation was that the sample set was exclusively male, preventing generalization to the females working in the hydraulic fracking procedure.

\section{Conclusion}

This research evaluated the respiratory health of a cross section of proppant workers from a proppant manufacturing facility. The research demonstrated that the worker group did not experience pulmonary impairment as compared to the general population in the US Ceramic proppant may be a safer alternative to high silica sand proppant for the oil and gas fracking industry.

\section{Acknowledgements}

Special thanks to Dr. Kate Wolfe-Quintero, Associate professor, Director of Graduate Studies, College of Public Health, University of South Florida, for her valuable time and guidance in preparation of this manuscript.

\section{References}

[1] UNEP Global Environmental Alert Service (GEAS) (2011) Athabasca Oil Sands, Require Massive Investments and Energy and Produce Massive Amounts of Oil and CO2. Alberta (Canada). United Nations Environment Program. http://na.unep.net/geas/getuneppagewitharticleidscript.php?article_id=54

[2] UNEP Global Environmental Alert Service (GEAS) (2011) Oil Palm Plantation: Threats and Opportunities for Tropical Ecosystems. United Nations Environment Program. http://www.unep.org/pdf/Dec_11_Palm_Plantations.pdf

[3] US Department of Labor, Bureau of Labor Statistics (BLS) (2008) Quarterly Census of Employment and Wages. US Department of Labor, Bureau of Labor Statistics, Washington DC. http://data.bls.gov/labjava/outside.jsp?survey=en

[4] Morbidity and Mortality Weekly Report (MMWR) (2008) Fatalities Among Oil and Gas Extraction Workers-United States, 2003-2006. 25 April 2008, 57(16), 429-431. http://www.cdc.gov/mmwr/preview/mmwrhtml/mm5716a3.htm

[5] Mader, D. (1989) Hydraulic Proppant Fracturing and Gravel Packing. Elsevier.

[6] Wu, T. and Wu B. (2012) Corrosion Resistance of Ceramic Proppant in BaO-CaO- $\mathrm{P}_{2} \mathrm{O}_{5}-\mathrm{Al}_{2} \mathrm{O}_{3}$ System. Corrosion Science, 63, 399-403. http://dx.doi.org/10.1016/j.corsci.2012.06.025

[7] Fuss-Dezelic, T. (2014) Test Proppants to Mitigate Respirable Dust Hazards. World Oil, 235, 86-89.

[8] Rosenman, K.D., Reilly, M.J. and Henneberger, P.K. (2003) Estimating the Total Number of Newly Recognized Silicosis Cases in the United States. American Journal of Industrial Medicine, 44, 141-147. http://dx.doi.org/10.1002/ajim.10243

[9] Wu, T., Wu, B. and Zhao, S. (2013) Acid Resistance of Silicon-Free Ceramic Proppant. Materials Letters, 92, $210-212$. http://dx.doi.org/10.1016/j.matlet.2012.10.124

[10] Rickards, A.R., Brannon, H.D. and Wood, W.D. (2006) High Strength Ultra-Light Weight Proppant Lends New Dimensions to Hydraulic Fracturing Applications. Production and Operations | Society of Petroleum Engineers, 21, 212221.

[11] Card, R.J., Howard, P.R. and Feraud, J.P. (1995) A Novel Technology to Control Proppant Back Production. Production and Operations | Society of Petroleum Engineers, 10, 271-276.

[12] Kulkarni, M.N. and Ochoa, O.O. (2012) Mechanism of Light Weight Proppant: A Discrete Approach. Composites Science and Technology, 72, 879-885. http://dx.doi.org/10.1016/j.compscitech.2012.02.017

[13] Kaufman, P.B., Anderson, R.W., Parker, M.A., Brannon, H.D., Neves, A.R., Abney, K.L., Joyce, S.A., Ziegler, M.J., Cortes, G.W.K.D.P. and Penny, G.S. (2007) Introducing New API/ISO Procedures for Proppant Testing. In: SPE Annual Technical Conference and Exhibition, Society of Petroleum Engineers. http://dx.doi.org/10.2118/110697-MS

[14] Ali, A., Road, J. and Pearce, W. (2009) Spirometry Pulmonary Function Testing in Clinical Practice. Springer-Verlag, London. 
[15] American Thoracic Society (ATS) (1987) Standardization of Spirometry-1987 Update. American Review of Respiratory Disease, 136, 1285-1298. http://dx.doi.org/10.1164/ajrccm/136.5.1285

[16] Chen, J., Lou, J. and Liu, Z. (2003) Pulmonary Function in Fur-Processing Workers: A Dose-Response Relationship. Archives of Environmental Health, 58, 37-47. http://dx.doi.org/10.3200/AEOH.58.1.37-41

[17] Wang, F., Zou, Y., Shen, Y., Zhong, Y., Lv, Y., Huang, D., Chen, K., Li, Q., Qing, L., Xia, B. and Su, C. (2015) Synergistic Impaired Effect between Smoking and Manganese Dust Exposure on Pulmonary Ventilation Function in Guangxi Manganese-Exposed Workers Healthy Cohort (GXMEWHC). PLoS ONE, 10, e0116558. http://dx.doi.org/10.1371/journal.pone.0116558

[18] Mandal, A. and Majumder, R. (2013) Pulmonary Function of Paint Workers from West Bengal, India. Progress in Health Sciences, 3, 110-121.

[19] Mandal, A. and Majumder, R. (2013) Assessment of Pulmonary Function of Cement Industry Workers from West Bengal India. Progress in Health Sciences, 3, 65.

[20] Abejie, B.A., Wang, X., Kales, S.N. and Christiani, D.C. (2010) Patterns of Pulmonary Dysfunction in Asbestos Workers: A Cross-Sectional Study. Journal of Occupational Medicine and Toxicology, 5, 12. http://dx.doi.org/10.1186/1745-6673-5-12

[21] Chattopadhyay, B.P, Gangopadhyay, P.K, Bandopadhyay, T.S. and Alam, J. (2006) Comparison of Pulmonary Function Test Abnormalities between Stone Crushing Dust Exposed and Nonexposed Agricultural Workers. Environmental Health and Preventive Medicine, 11, 191-198. http://dx.doi.org/10.1007/BF02905278

[22] Hankinson, J.L., Odencrantz, J.R. and Fedan, K.B. (1999) Spirometric Reference Values from a Sample of the General US Population. American Journal of Respiratory and Critical Care Medicine, 159, 179-187. http://dx.doi.org/10.1164/ajrccm.159.1.9712108

[23] Schwartz, J., Katz, S.A., Fegley, R.W. and Tockman, M.S. (1988) Sex and Race Differences in the Development of Lung Function1-5. American Review of Respiratory Disease, 138, 1415-1421. http://dx.doi.org/10.1164/ajrccm/138.6.1415

[24] Glindmeyer, H.W., Lefante, J.J., McColloster, C., Jones, R.N. and Weill, H. (1995) Blue-Collar Normative Spirometric Values for Caucasian and African-American Men and Women Aged 18 to 65. American Journal of Respiratory and Critical Care Medicine, 151, 412-422. http://dx.doi.org/10.1164/ajrccm.151.2.7842200

[25] Mannino, D.M., Gagnon, R.C., Petty, T.L. and Lydick, E. (2000) Obstructive Lung Disease and Low Lung Function in Adults in the United States: Data from the National Health and Nutrition Examination Survey, 1988-1994. Archives of Internal Medicine, 160, 1683-1689. http://dx.doi.org/10.1001/archinte.160.11.1683

[26] Peto, R., Speizer, F.E., Cochrane, A.L., Moore, F., Fletcher, C.M., Tinker, C.M., Higgins, I.T.T., Gray, R.G., Richards, S.M., Gilliland, J. and Norman-Smith, B. (1983) The Relevance in Adults of Air-flow Obstruction, but Not of Mucus Hypersecretion, to Mortality from Chronic Lung Disease: Results from 20 Years of Prospective Observation. American Review of Respiratory Disease, 128, 491-500. http://dx.doi.org/10.1164/arrd.1983.128.3.491

[27] Burrows, B., Lebowitz, M.D., Camilli, A.E. and Knudson, R.J. (1986) Longitudinal Changes in Forced Expiratory Volume in One Second in Adults: Methodologic Considerations and Findings in Healthy Nonsmokers. American Review of Respiratory Disease, 133, 974-980.

[28] Asai, M., Tanaka, T., Kozu, R., Kitagawa, C., Tabusadani, M. and Senjyu, H. (2015) Effect of a Chronic Obstructive Pulmonary Disease (COPD) Intervention on COPD Awareness in a Regional City in Japan. Internal Medicine, 54, 163-169. http://dx.doi.org/10.2169/internalmedicine.54.2916

[29] Holguin, F., Folch, E., Redd, S.C. and Mannino, D.M. (2005) Comorbidity and Mortality in COPD-Related Hospitalizations in the United States, 1979 to 2001. Chest Journal, 128, 2005-2011.

[30] Hole, D.J., Watt, G.C.M., Davey-Smith, G., Hart, C.L., Gillis, C.R. and Hawthorne, V.M. (1996) Impaired Lung Function and Mortality Risk in Men and Women: Findings from the Renfrew and Paisley Prospective Population Study. British Medical Journal, 313, 711-715. http://dx.doi.org/10.1136/bmj.313.7059.711

[31] Wahba, W.M. (1983) Influence of Aging on Lung Function-Clinical Significance of Changes from Age Twenty. Anesthesia \& Analgesia, 62, 764-776. http://dx.doi.org/10.1213/00000539-198308000-00011 